\title{
FORÇAS DE ATRITO EM SILOS VERTICAIS DE PAREDES LISAS EM DIFERENTES RELAÇÕES ALTURA/DIÂMETRO
}

\author{
JOSÉ P. LOPES NETO ${ }^{1}$, JOSÉ W. B. DO NASCIMENTO ${ }^{2}$, RAFAEL C. SILVA ${ }^{3}$
}

RESUMO: Para desenvolver um projeto de silo, é necessário que fatores como o fluxo e cargas sejam criteriosamente avaliados. Portanto, como objetivo principal deste trabalho destacam-se a mensuração, a análise e a comparação com normais internacionais das forças de atrito nas paredes de um silo cilíndrico de fundo plano. Para a medição das forças de atrito, foram utilizados dois conjuntos de três células de carga e um sistema de aquisição de dados. O silo foi carregado concentricamente com areia seca e descarregado concêntrica e excentricamente a partir de duas excentricidades através de orifícios de $80 \mathrm{~mm}$ de diâmetro. Os resultados evidenciam que o modelo de silo-piloto é adequado para a medição das forças de atrito nas paredes e que os valores teóricos propostos pelas normas AS 3774 e DIN 1055 são mais adequados para representar as forças de atrito, tanto no descarregamento concêntrico quanto no excêntrico para todas as relações H/D estudadas.

PALAVRAS-CHAVE: normas internacionais, fundo plano, excentricidade, descarregamento, silo cilíndrico.

\section{FRICTION FORCES IN VERTICAL SILOS WITH SMOOTH WALLS IN DIFFERENT HEIGHT/DIAMETER RATIOS}

\begin{abstract}
For the development of silo designs, it is necessary that factors such as flow and loads be carefully evaluated. Therefore, the main objective of this work is to measure, analyze and evaluate international standards of friction forces on the walls of a cylindrical silo with flat bottom. For the measurement of friction forces, two sets of three load cells and a data acquisition system were used. The silo was concentrically loaded with dry sand, and concentrically and eccentrically discharged from two eccentricities through holes of $80 \mathrm{~mm}$ diameter. The results show that the pilot silo model is suitable for measuring the friction forces on the walls, and that the theoretical values proposed by AS 3774 and DIN 1055 standards are more appropriate for the representation of friction forces in both concentric and eccentric discharging for all studied height/diameter ratios.
\end{abstract}

KEYWORDS: international standards, flat bottom, eccentricity, discharging, cylindrical silo.

\section{INTRODUÇÃO}

Silos são estruturas destinadas ao armazenamento de produtos sólidos, sendo largamente empregados em estabelecimentos agrícolas e portos marítimos e fluviais para conservação e comercialização de cereais.

Em geral, as indústrias têm problemas com seus produtos, sejam eles na forma granular ou pulverulenta, uma vez que os sólidos, ao contrário dos líquidos, transmitem tensões de cisalhamento em condições estáticas e, quando comprimidos, aumentam sua coesão, proporcionando interferências na descarga e, em consequência, paralisações parciais ou totais do processo industrial, o que pode acarretar sérios prejuízos econômicos (LOPES NETO et al., 2008).

\footnotetext{
${ }^{1}$ Eng $^{\circ}$ Agrícola, Prof. Doutor, Departamento de Engenharia Agrícola, UFCG/Campina Grande - PB, Fone: (83) 2101-1490,

lopesneto@deag.ufcg.edu.br.

${ }^{2}$ Eng $^{\circ}$ Agrícola, Prof. Doutor, Departamento de Engenharia Agrícola, UFCG/Campina Grande - PB, wallace@ deag.ufcg.edu.br.

${ }^{3}$ Eng $^{\mathbf{o}}$ Agrícola, Mestrando, Departamento de Engenharia Agrícola, UFCG/Campina Grande - PB, rafael_brazil@ hotmail.com.

Recebido pelo Conselho Editorial em: 24-8-2012

Aprovado pelo Conselho Editorial em: 25-8-2013
} 
SCHULZE (2008) comenta que quando, o projeto de uma instalação industrial é desenvolvido, normalmente, a atenção exigida às unidades armazenadoras é desprezada pelo fato de estes elementos não participarem efetivamente das principais operações industriais, tais como moagem, filtragem ou mistura. Contudo, silos mal projetados podem interferir negativamente nas etapas de produção e qualidade do produto.

Estas interferências podem apresentar-se na forma de problemas funcionais, como a formação de arcos coesivos que reduzem ou até mesmo impedem a descarga do produto armazenado, além do tempo de armazenagem, que são fatores que podem afetar consideravelmente o tipo de fluxo dos produtos e favorecer a formação desses arcos (LOPES NETO et al., 2009), ou na forma de problemas estruturais, como deformações e ruptura da estrutura. Desde o final do século XIX vemse aprimorando métodos estruturais de silos para armazenamento de produtos agrícolas; no entanto, muitos dos problemas observados na prática ainda persistem, uma vez que o comportamento do material granular e as pressões que exercem sobre paredes internas do silo ainda não estão completamente entendidos (AYUGA, 2008; DOGANGUN et al., 2009; NIELSEN, 2008).

Como agravante, sabe-se que as imperfeições das paredes e a excentricidade de carga e descarga podem contribuir para o desenvolvimento de ações não uniformes ao longo da profundidade dos silos, o que, no caso das forças de atrito, podem ocasionar o surgimento de momentos fletores diametrais. Em função deste cenário, este trabalho teve como objetivo mensurar a intensidade das forças de atrito em um silo-piloto cilíndrico de fundo plano, em três relações H/D com descargas concêntrica e excêntrica, e comparar seus resultados com os preconizados por diferentes normas internacionais.

\section{MATERIAL E MÉTODOS}

Para a realização da pesquisa, foi projetado, construído, instrumentado e ensaiado um silo cilíndrico metálico com paredes lisas e fundo plano. Sua instalação foi junto à Universidade Federal de Campina Grande (UFCG), na Paraíba, e as análises foram realizadas de janeiro a abril de 2008. As paredes foram confeccionadas em chapa metálica com espessura de 1,98 mm. A escolha dessa espessura baseou-se na necessidade de se obter um silo com paredes suficientemente rígidas de modo a não apresentarem deformações durante os ensaios.

O corpo do silo foi dividido em dois anéis, sendo denominados de anel I o anel inferior e de anel II o anel superior. O anel I foi obtido pela união de duas chapas metálicas com dimensões de $2 \mathrm{~m}$ x $1 \mathrm{~m}$ (largura x altura), resultando em um cilindro de $1 \mathrm{~m}$ de profundidade, 1,24 $\mathrm{m}$ de diâmetro e $1,2 \mathrm{~m}^{3}$ de volume. O mesmo procedimento foi adotado para o anel II, com a diferenciação do uso de quatro chapas metálicas, resultando em um cilindro de $2 \mathrm{~m}$ de profundidade, $1,24 \mathrm{~m}$ de diâmetro e 2,4 $\mathrm{m}^{3}$ de volume. Desta forma, foram obtidos dois anéis com relações altura/diâmetro (H/D) iguais a 0,8 (anel I) e 1,6 (anel II). Após a montagem do silo pelo posicionamento do anel II sobre o anel I, obteve-se um silo vertical cilíndrico com capacidade total de armazenagem de 3,6 $\mathrm{m}^{3}$, profundidade (z) igual a 3 m e relação H/D final igual a 2,4 (Figura 1). 


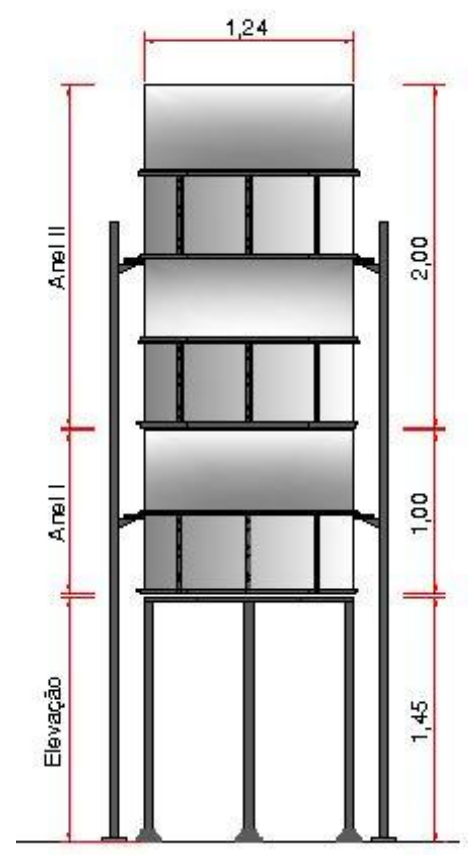

FIGURA 1. Representação gráfica do silo-piloto e fundo plano. Graphical representation of the pilot silo and flat bottom.

Os orifícios de descarga de diâmetro igual a $80 \mathrm{~mm}$ foram posicionados para permitir tanto uma descarga concêntrica (D 1) quanto descargas excêntricas relativas a 50 (D 2) e 75\% (D 3) de distância do centro (Figura 2). A instrumentação do silo deu-se pela utilização de seis células de carga com capacidade igual a $5,4 \mathrm{kN}$, fixadas aos anéis e conectadas às colunas do corpo. Cada anel foi instrumentado com três células de carga de modo que sua disposição permitisse um ângulo de $120^{\circ}$ uma das outras. Deste modo, cada sensor registraria a força de atrito para uma determinada porção diametral das paredes nos dois anéis.

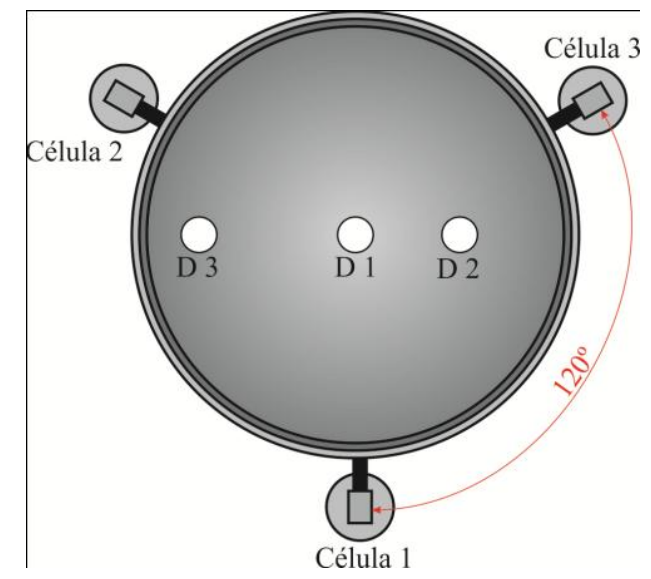

FIGURA 2. Disposição dos orifícios e células de carga. Arrangement of holes and load cells.

Previamente à instrumentação do silo, cada sensor foi conectado a um sistema de aquisição de dados Modelo Spider8 $600 \mathrm{~Hz}$ de fabricação da HBM. As células de carga foram calibradas a partir de volumes de água previamente definidos. A cada acréscimo de volume, o sistema registrava uma variação de potencial elétrico até a obtenção de um quadro que expressasse uma relação confiável entre carga/variação elétrica para cada sensor.

Os ensaios foram iniciados pelo carregamento concêntrico do silo e, após um período de armazenagem de $1 \mathrm{~h}$, efetuou-se o descarregamento pelo orifício de descarga central (D1). Na segunda etapa, o silo foi novamente preenchido concentricamente e, após o período de 
armazenagem definido, ocorreu seu completo descarregamento pelo orifício de descarga denominado D2. Por fim, após o carregamento concêntrico do silo, foi acionado o orifício de descarga denominado de D3. Foram realizadas quatro repetições para cada descarregamento, por ser comumente um número considerado como padrão para ensaios desta natureza.

Como produto armazenável, optou-se por utilizar areia seca, com peso específico aparente de aproximadamente 14 a $17 \mathrm{kN} \cdot \mathrm{m}^{-3}$, com uniformidade de partículas, facilidade de aquisição e que proporciona elevadas cargas na estrutura, assegurando, desta forma, que os dados obtidos pudessem ser considerados como quantitativamente representativos dos esforços desenvolvidos. Foram determinadas as propriedades de fluxo da areia lavada através do aparelho de cisalhamento de translação conhecido internacionalmente por Jenike Shear Cell, recomendado pela BMHB (1985). As propriedades determinadas em ensaios de laboratórios foram: peso específico em função da consolidação $(\gamma)$, ângulo de atrito interno $(\varnothing)$, efetivo ângulo de atrito interno $(\delta)$ e ângulo de atrito entre o produto e o material da parede do silo $\left(\varnothing_{\mathrm{w}}\right)$.

Para a determinação do ângulo de atrito com a parede $\left(\varnothing_{\mathrm{w}}\right)$, foi adotado o mesmo equipamento descrito acima, mas com a utilização de uma amostra do material da parede do silo-piloto, bem como outros níveis de carga $(50 ; 40 ; 30 ; 20 ; 10$ e 4,4 N). O fator k foi determinado conforme EN 1991-4 (2006). Foi analisado ainda o somatório da força de atrito entre os dois anéis, sendo representado pela relação $\mathrm{H} / \mathrm{D}=2,4$, com posterior comparação dos dados aos obtidos teoricamente pelas normas internacionais EN 1991-4 (2006), ISO 11697 (1995), AS 3774 (1996) e DIN 1055 (1987).

Neste trabalho, os valores téoricos de pressão de atrito obtidos através das diferentes normas foram transformados em força de atrito para posterior comparação aos experimentais. Basicamente, todas essas normas internacionais utilizam-se da mesma expressão para a estimativa das pressões horizontais de carregamento $\left(\mathrm{P}_{\mathrm{hc}}\right)$, equação (1), diferenciando apenas para o descarregamento a adoção de diferentes coeficientes de sobrepressão $\left(\mathrm{C}_{\mathrm{sp}}\right)$.

$$
P_{h c}=\frac{\gamma R}{\mu}\left(1-e^{\frac{-z k \mu}{R}}\right)
$$

Sendo:

Phc - pressão horizontal de carregamento, $\mathrm{Pa}$;

$\gamma$ - peso específico consolidado, N.m ${ }^{-3}$;

$\mathrm{R}$ - raio hidráulico, $\mathrm{m}$;

$\mu$ - coeficiente de atrito do produto com a parede, adimensional;

$\mathrm{k}$ - relação entre pressão horizontal e vertical, e

$\mathrm{z}$ - profundidade do silo, $\mathrm{m}$.

Para o descarregamento concêntrico, o coeficiente de sobrepressão $\left(\mathrm{C}_{\mathrm{sp}}\right)$ adotado pela norma EN 1991-4 (2006) foi igual a 1,1, enquanto para as descargas excêntricas, existe um acréscimo de pressão $\left(\mathrm{P}_{\mathrm{ad}}\right)$ ao valor obtido para o descarregamento, devendo o mesmo ser tomado pelas equações 2, 3, 4 e 5, a seguir:

$$
P_{a d}=C_{a d} P_{h d}
$$

$\mathrm{O}$ valor de $\mathrm{C}_{\mathrm{ad}}$ deve ser tomado em função da relação $\mathrm{H} / \mathrm{D}$ do silo, como segue:

Para H/D > 1,2;

Sendo:

$$
C_{a d}=0,42 C_{o p}\left[1+2 E^{2}\right]\left(1-\exp \left\{-1,5\left[\left(\frac{H}{D}\right)-1\right]\right\}\right)
$$

$\mathrm{C}_{\mathrm{op}}=$ fator de referência do produto para acréscimo na descarga.

Para H/D $\leq 1,2 ; \mathrm{C}_{a d}$ é dado pelo maior valor entre a equação 4 e o valor "0".

$$
C_{a d}=0,272 C_{o p}\left\{\left(\frac{H}{D}-1+E\right)\right\}
$$


(5)

$$
E=2 \frac{e}{D}
$$

Em que:

$$
e=\max \left(e_{f}, e_{0}\right)
$$

Sendo $e_{0}=$ a excentricidade a partir do centro do orifício de descarga (decimal).

Para a norma ISO 11697 (1995), o valor de $C_{\mathrm{sp}}$ varia em função da relação H/D sendo considerado 1,0 e 1,35 para as relações $\mathrm{H} / \mathrm{D} \leq 1,0$ e $\mathrm{H} / \mathrm{D} \geq 1,5$, respectivamente. Para a relação $\mathrm{H} / \mathrm{D}$, variando entre 1,0 e 1,5 , o valor adotado para $\mathrm{C}_{\mathrm{sp}}$ deve obedecer à equação 6 , a seguir:

$$
\mathrm{C}_{\mathrm{sp}}=1,0+0,7(\mathrm{H} / \mathrm{D}-1,0)
$$

Para a norma AS 3774 (1996), utilizou-se do maior valor de $C_{\text {sp }}$ entre as equações 7 e 8, a seguir:

$$
\begin{aligned}
& C_{s p}=\left[7,6\left(\frac{H}{D}\right)^{0,06}-6,4\right] \\
& \mathrm{C}_{\mathrm{sp}}=1,2 \mathrm{Cc}
\end{aligned}
$$

Sendo:

Cc - coeficiente de geometria do fluxo igual a 1,0 para fluxo assimétrico e 1,2 para fluxo plano.

Para a norma DIN 1055 (1987), o coeficiente adotado foi constante e igual a 1,1.

\section{RESULTADOS E DISCUSSÃO}

Nas Tabelas 1 e 2, constam os limites inferior e superior e o valor médio de peso específico consolidado, ângulo de atrito com a parede, ângulo de atrito interno e efetivo ângulo de atrito interno, onde são comparados aos preconizados por algumas das normas. O peso específico consolidado representa a razão entre a massa de uma porção de produto pelo seu volume ocupado, estando esta porção de massa sob ação de forças de compressão.

Pode-se destacar, na Tabela 1, que a areia lavada apresenta variação entre os limites de suas propriedades de $0,5 \mathrm{kN} . \mathrm{m}^{-3}$ e $1,1^{\circ}$ para o peso específico consolidado e ângulo de atrito com a parede, respectivamente. Na Tabela 2 , a variação encontrada foi de 7,3 e 4,2 $2^{\circ}$ para o ângulo de atrito interno e efetivo ângulo de atrito interno, respectivamente. Quanto aos valores normatizados,

\begin{tabular}{|c|c|c|c|c|}
\hline \multirow[t]{2}{*}{ Produto analisado } & \multicolumn{2}{|c|}{$\begin{array}{l}\text { Peso específico consolidado } \\
\left(\gamma-\mathrm{kN} \cdot \mathrm{m}^{-3}\right)\end{array}$} & \multicolumn{2}{|c|}{$\begin{array}{l}\text { Ângulo de atrito com a parede } \\
\qquad\left(\emptyset_{w}-{ }^{\circ}\right)\end{array}$} \\
\hline & Inferior & Superior & Inferior & Superior \\
\hline Areia & 16,5 & 17,0 & 26,2 & 27,3 \\
\hline Média & \multicolumn{2}{|c|}{16,8} & \multicolumn{2}{|c|}{$26,8^{\circ}$} \\
\hline AS 3774 & 15,0 & 17,0 & 30,0 & 35,0 \\
\hline EN 1991-4 & 14,0 & 16,0 & 26,2 & 33,5 \\
\hline DIN 1055 & \multicolumn{2}{|c|}{16,0} & \multicolumn{2}{|c|}{21,8} \\
\hline ВМНВ & 14,0 & 17,0 & 21,8 & 33,0 \\
\hline
\end{tabular}
observa-se grande consonância com os dados experimentais, o que confirma a credibilidade das propriedades descritas anteriormente.

TABELA 1. Peso específico consolidado e ângulo de atrito com a parede. Consolidated specific weight and friction angle on the wall.

TABELA 2. Ângulo de atrito interno e efetivo ângulo de atrito. Internal friction angle and effective friction angle. 


\begin{tabular}{cccccc}
\hline \multirow{2}{*}{ Produto analisado } & \multicolumn{2}{c}{ Ângulo de atrito interno } & \multicolumn{2}{c}{$\begin{array}{c}\text { Efetivo ângulo de atrito interno } \\
\left(\varnothing-{ }^{\mathbf{o}}\right)\end{array}$} \\
\cline { 2 - 7 } & Inferior & Superior & Inferior & Superior \\
\cline { 2 - 7 } Areia & 32,2 & 39,5 & 36,7 & 40,9 \\
Média & & 36,2 & & 35,0 & 39,3 \\
\hline AS 3774 & $* *$ & & $* *$ & & 40,0 \\
EN 1991-4 & 33,0 & 39,2 & & 36,0 & \\
DIN 1055 & $* *$ & $* *$ & 33,0 & & 40,0 \\
BMHB & $* *$ & $* *$ & & &
\end{tabular}

Para o fator k, (Figura 3), definido como a relação entre a pressão horizontal e a vertical em qualquer ponto de uma massa granular, os valores encontrados foram 0,28 e 0,34 para os limites inferior e superior, respectivamente. Na mesma figura, pode-se notar que os valores experimentais encontram-se entre a faixa de variação das normas AS 3774 (1996) e EN 1991-4 (2006), enquanto os resultados da DIN 1055 (1985) foram os que mais se afastaram dos valores experimentais, superestimando-os em $45 \%$.

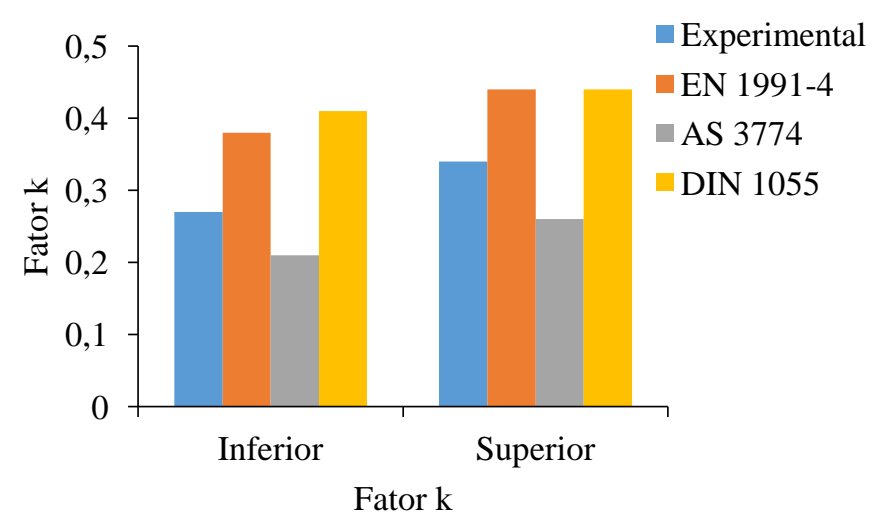

FIGURA 3. Variação do fator k. Variation of $\mathbf{k}$ factor.

NASCIMENTO \& CALIL JUNIOR (2009), ao medir o fator k para o carregamento de um silo cilíndrico metálico de paredes lisas, obtiveram valores iguais a 0,455;0,320 e 0,298 para grãos de milho, soja e ração avícola. É importante destacar que a correta determinação do fator $\mathrm{k}$ é imprescindível para um projeto seguro de silos, uma vez que este fator representa a porcentagem da distribuição das pressões em função da relação H/D. Durante o carregamento do silo, procurou-se manter uma vazão mássica média de $0,423 \mathrm{~kg} . \mathrm{s}^{-1}$. Já no descarregamento, a vazão média foi de, aproximadamente, $5,635 \mathrm{~kg} . \mathrm{s}^{-1}$, o que produziu uma velocidade de deslizamento da areia na parede do silo de, aproximadamente, $0,00283 \mathrm{~m} . \mathrm{s}^{-1}$.

$\mathrm{Na}$ Figura 4, força de atrito durante o carregamento do silo, pode-se observar que as normas reproduzem resultados satisfatórios até a relação $\mathrm{H} / \mathrm{D}=1,6$ sendo que, a partir desta relação, apenas as normas AS 3774 (1996) e DIN 1055 (1987) reproduzem satisfatoriamente os resultados obtidos, enquanto as demais normas chegam a atingir valores $24 \%$ acima dos encontrados na prática. 


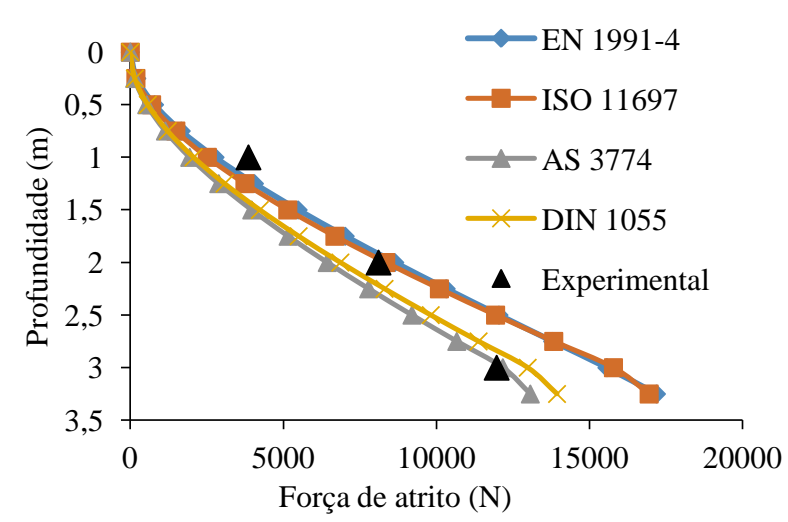

FIGURA 4. Força de atrito no carregamento concêntrico. Friction force in the concentric loading.

A diferença entre os resultados das normas para a força de atrito durante o carregamento reside, basicamente, na formulação proposta para o fator k. A norma AS 3774 (1996) é a norma que adota os menores valores para $\mathrm{k}$, o que explica seus reduzidos valores quando comparados aos experimentais. CHEUNG \& CALIL JUNIOR (2009), ao medir as forças de atrito no carregamento concêntrico em um silo esbelto cilíndrico, encontrou valores da ordem de $2.850 ; 4.641$ e $6.586 \mathrm{~N}$ para as profundidades de 1, 2 e $3 \mathrm{~m}$, respectivamente. Esses resultados representam uma diferença de 9,$1 ; 25,6$ e 29,8\% para as mesmas profundidades da presente pesquisa, respectivamente.

A seguir, encontram-se os gráficos relativos às forças de atrito no descarregamento em comparação aos valores preditos pelas normas internacionais EN 1991-4 (2006), ISO 11697 (1995), AS 3774 (1996) e DIN 1055 (1987). É importante salientar que os gráficos teóricos foram construídos com base nos valores das propriedades de fluxo da areia seca obtidos experimentalmente e não com base nas propriedades preditas pelas normas. Isso foi executado no sentido de obter valores mais próximos aos experimentais.

Todas as quatro normas utilizadas como comparativo baseiam-se nas deduções de Janssen para a predição da pressão estática em silos. Como ponto de diferenciação, cada norma costuma adotar diferentes coeficientes de multiplicação às pressões de carregamento para a obtenção dos valores de descarga, o que tende a gerar diferentes resultados de pressão para o mesmo silo.

Para a Figura 5, destaca-se a boa aproximação de todas as normas para a primera relação H/D; já para a relação $\mathrm{H} / \mathrm{D}=1,6$ é notado um distanciamento dos valores teóricos com diferença superior a 24\% obtida para a norma ISO 11697 (1995). Para a relação H/D =2,4, o que representa um silo classificado como esbelto, de modo geral, todas as normas analisadas foram insatisfatórias ao prever as forças experimentais, com destaque para a maior diferença de $42 \%$ obtida para a ISO 11697 (1995).

Na Figura 6, descarga com 50\% de excentricidade, foi notado o mesmo comportamento descrito anteriormente, com destaque para maior afastamento entre os valores experimentias e teóricos obtido para a maior relação H/D, sendo de 51\% de superioridade para a ISO 11697 (1995) e média de $37 \%$ para as demais normas comparadas. Este resultado evidencia que os coeficientes para o descarregamento para maiores relações H/D e fator k, adotados pela norma ISO 11697 (1995), podem reproduzir valores acima dos reais, resultando em incorreto dimensionamento de silos verticais. 


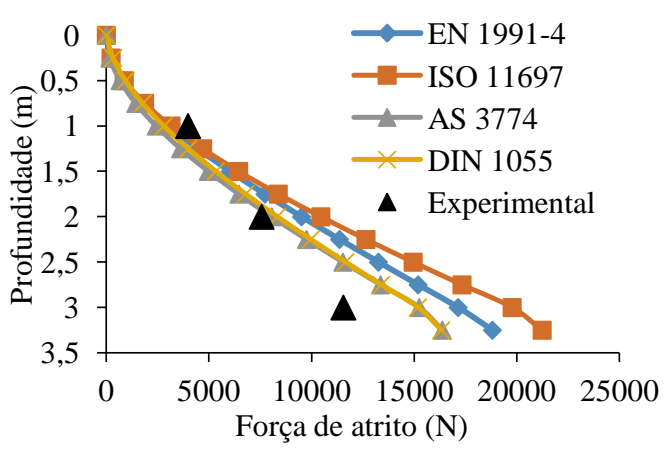

FIGURA 5. Forças de atrito para a descarga concêntrica. Friction forces for the concentric discharging.

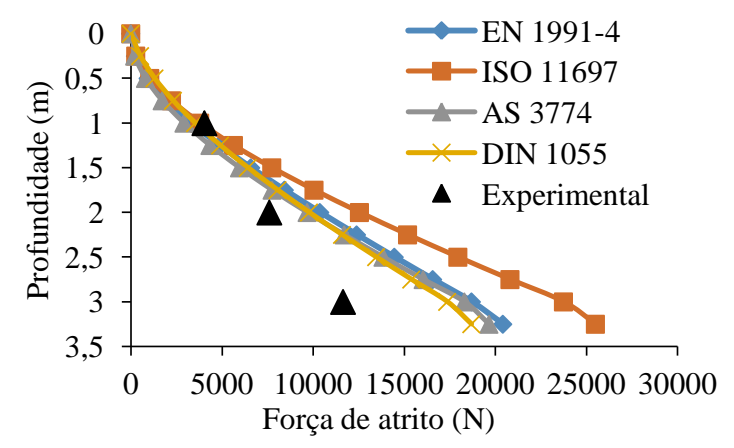

FIGURA 6. Forças de atrito para a descarga excêntrica a $50 \%$. Friction forces for the $50 \%$ eccentricity discharging.

Na Figura 7, representativa à descarga com $75 \%$ de excentricidade, pode-se notar que, para a relação H/D inicial $(0,8)$, os valores experimentais superaram os teóricos, enquanto, tanto para relação H/D 1,6 quanto para 2,4, com exceção da norma ISO 11697 (1995), todas as outras formulações propostas enquadram-se nos valores obtidos no experimento. Este comportamento indica que as normas tendem a promover melhores aproximações para silos com maiores excentricidades de descarga. A diferença encontrada entre a norma ISO 11697 (1995) e os valores experimentais foi de 11 e $26 \%$ para as relações H/D iguas a 1,6 e 2,4, respectivamente.

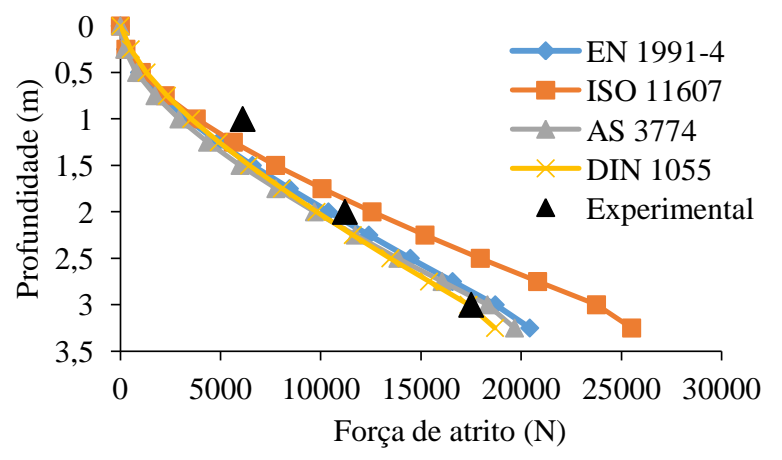

FIGURA 7. Forças de atrito na descarga com $75 \%$ de excentricidade. Friction forces in the $\mathbf{7 5 \%}$ eccentricity discharging.

Na Tabela 3, encontram-se os coeficientes de sobrecarga experimentais para os descarregamentos concêntrico e excêntrico. Foram observados os maiores valores de sobrecarga para as maiores profundidades, especialmente para as descargas concêntrica e excêntrica a $75 \%$ (médias iguais a 1,28). Segundo CHEUNG \& CALIL JUNIOR (2009), os maiores valores encontrados de sobrecarga em seus estudos para grãos e ração de aves foram da ordem de 1,1, o que representa uma diferença de $19 \%$. Acredita-se que variações no fator $\mathrm{k}$, nas propriedades da areia durante os ensaios e as particularidades de cada experimento, possam ter gerado coeficientes superiores aos encontrados em outros estudos. 
TABELA 3. Coeficientes de sobrecarga durante o descarregamento. Overload coefficients during discharging.

\begin{tabular}{cccc}
\hline \multirow{2}{*}{ Relação H/D } & \multicolumn{3}{c}{ Descarga } \\
\cline { 2 - 4 } & Concêntrica & $50 \%$ & $75 \%$ \\
\hline 0,8 & 1,23 & 1,21 & 1,27 \\
1,6 & 1,30 & 1,22 & 1,27 \\
2,4 & 1,32 & 1,33 & 1,30 \\
\hline Média & 1,28 & 1,25 & 1,28 \\
\hline Desvio Padrão & 0,047 & 0,066 & 0,017 \\
\hline CV & 3,7 & 5,3 & 1,3 \\
\hline
\end{tabular}

$\overline{\mathrm{CV}}$ - coeficiente de variação

\section{CONCLUSÕES}

Os valores das propriedades de fluxo enquadraram-se dentro dos limites recomendados pelas normas analisadas;

$\mathrm{O}$ fator $\mathrm{k}$ aproximou-se dos valores propostos pelas normas, o que indica adequada confiabilidade dos resultados, sendo mais bem representado pela norma EN 1991-4 (2006);

Os valores experimentais de força de atrito obtidos para o carregamento foram mais bem representados pelas normas EN 1991-4 (2006) e ISO 11697 (1995) para a relação H/D = 1,6 e pelas normas AS 3774 (1996) e DIN 1055 (1987) para a relação H/D = 2,4. Já para o descarregamentos concêntrico e excêntrico, as normas AS 3774 (1996) e DIN 1055 (1987) foram as que apresentaram valores mais próximos aos obtidos experimentalmente em todas as relações H/D analisadas. Dentre as demais normas, a que proporcionou resultados menos representativos aos experimentais foi a ISO 11697 (1995).

Para todas as situações de descarga, os coeficientes encontrados variaram de 1,2 a 1,3, devendo estes serem utilizados em projetos de silos verticais cilíndricos.

\section{AGRADECIMENTOS}

Os autores agradecem ao Grupo de Estudos em Silos (Silos) e ao Grupo de Estudos em Construções Rurais e Ambiência (GCAMB) da Universidade Federal de Campina Grande pelo apoio para a realização desta pesquisa.

\section{REFERÊNCIAS}

AS 3774. Loads on bulk containers. Sydney: Australian Standard, 1996. 76p.

AYUGA, F. Some unresolved problems in the design of steel cylindrical silos. In: CHEN, J. F.

CHEUNG, A. B.; CALIL JUNIOR, C. Modelo estocástico de pressões de produtos armazenados para a estimativa da confiabilidade estrutural de silos esbeltos. Caderno de Engenharia de Estruturas, São Carlos, v.11, n.48, p. 1-22, 2009.

DIN 1055. Design loads for buildings: loads in silo bins. Berlin: Deutsche Norm, 1987. 6p.

DOGANGUN, A.; KARACA, Z.; DURMUS, A.; SEZEN, H. Cause of damage and failures in silo structures. Journal of Performance of Constructed Facilities New York, v. 23, p. 65-71, 2009.

EN 1991-4. Eurocode 1 Part 4. Actions on silos and tanks. Bruxelas: European Standard, 2006. $122 \mathrm{p}$.

ISO 11697. Bases for design of structures: loads due to bulk materials. Switzerland: International Standard, 1995. 18p. 
LOPES NETO, J. P.; NASCIMENTO, J. W. B.; CALIL JUNIOR, C. Análise estrutural de silos metálicos prismáticos. Ciência e Agrotecnologia, Lavras, v.32, n.4, p. 1.252-1.258, 2008.

LOPES NETO, J. P.; SILVA, V. R.; NASCIMENTO, J. W. B. Propriedades de fluxo de produtos pulverulentos alimentícios. Revista Brasileira de Engenharia Agrícola e Ambiental, Campina Grande, v.13, n.5, p. 639-644, 2009.

NASCIMENTO, F.C; CALIL JUNIOR, C. A relação entre as pressões horizontais e verticais em silos elevados: o parâmetro k. Cadernos de Engenharia de Estruturas, São Carlos, v. 11, n. 52, p. 17-37, 2009.

NIELSEN, J. From silo phenomena to load models. In: INTERNATIONAL CONFERENCE ON STRUCTURES AND GRANULAR SOLIDS, 2008, Edinburgh. Proceedings...Edinburgh: The Royal Society of Edinburgh, 2008.

SCHULZE, D. Powders and bulk solids. Behavior, characterization, storage and flow. Berlin: Springer, 2008. 517p. 